\title{
Analysis of the Efficiency and Prognostic Value of the Sentinel Node Technique in Oral Squamous Cell Carcinoma after Seven Years
}

\author{
Maria Suárez-Ajuria ${ }^{1}$, Abel García-García ${ }^{1,2}$, José M. Suárez-Peñaranda ${ }^{3,4}$, Miguel Garrido-Pumar ${ }^{5}$, \\ Cintia M. Chamorro-Petronacci ${ }^{2, * \mathbb{D}}$, José M. Somoza-Martín ${ }^{1}$ and Mario Pérez-Sayáns ${ }^{1,2} \mathbb{D}$ \\ 1 Oral Medicine and Surgery Unit, Faculty of Dentistry, Universidade de Santiago de Compostela, \\ 15782 Santiago de Compostela, Spain; mariasuaj@gmail.com (M.S.-A.); abel.garcia@usc.es (A.G.-G.); \\ cinolo@gmail.com (J.M.S.-M.); perezsayans@gmail.com (M.P.-S.) \\ 2 Instituto de Investigación Sanitaria de Santiago (IDIS), 15782 Santiago de Compostela, Spain \\ 3 Department of Forensic Sciences and Pathology, University of Santiago de Compostela, \\ 15782 Santiago de Compostela, Spain; jm.penaranda@gmail.com \\ 4 Department of Pathology, Clinical University Hospital, 15782 Santiago de Compostela, Spain \\ 5 Department of Nuclear Medicine, Santiago de Compostela's University Hospital, \\ 15782 Santiago de Compostela, Spain; Miguel.Garrido.Pumar@sergas.es \\ * Correspondence: cintiamica.chamo@yahoo.es
}

Citation: Suárez-Ajuria, M.; García-García, A.; Suárez-Peñaranda, J.M.; Garrido-Pumar, M.;

Chamorro-Petronacci, C.M.; Somoza-Martín, J.M.; Pérez-Sayáns, M. Analysis of the Efficiency and Prognostic Value of the Sentinel Node Technique in Oral Squamous Cell Carcinoma after Seven Years. Medicina 2021, 57, 1092. https:/ / doi.org/10.3390/medicina57101092

Academic Editor: Ilana Kaplan

Received: 18 August 2021

Accepted: 10 October 2021

Published: 12 October 2021

Publisher's Note: MDPI stays neutral with regard to jurisdictional claims in published maps and institutional affiliations.

Copyright: (C) 2021 by the authors. Licensee MDPI, Basel, Switzerland. This article is an open access article distributed under the terms and conditions of the Creative Commons Attribution (CC BY) license (https:/ / creativecommons.org/licenses/by/ $4.0 /)$.

\begin{abstract}
Background and objectives: The purpose of this study was to analyse the diagnostic and prognostic efficiency of the sentinel lymph node biopsy technique (SLNB). Materials and Methods: This is a prospective observational study performed by the Hospital Complex in Santiago de Compostela (CHUS) in Spain, between February 2013 and June 2020. The study included 60 patients, who had been diagnosed with OSCC in stage T1/T2N0M0. Results: 10 patients (16.7\%) presented with $\mathrm{SN}+$ (sentinel node positive). The majority $(80 \%)$ only presented subcapsular affection, however one case also presented with extracapsular affection. Using the Kaplan-Meier curves, we determined that the average survival estimation for $\mathrm{SN}-$ patients was 74.0 months (C195\% 67.6-80.5) and it was 45.4 months (CI95\% 10.9-24.0) for $\mathrm{SN}+$ patients $(p=0.002)$. $\mathrm{SN}+$ patients presented an $\mathrm{OR}=11.000$ (CI95\% 2.393-50.589, $p=0.002)$ for cancer-related mortality. In terms of the diagnostic performance of the SN (sentinel node) test, a 55\% sensitivity, a 100\% specificity, 100\% PPV and a $84 \%$ NPV were obtained. The analysis using ROC (receiver operating characteristic) curves revealed an AUC $=0.671$ (C195\% 0.492-0.850, $p=0.046)$. Conclusions: SLNB seems to be an adequate technique for the detection of hidden metastases.
\end{abstract}

Keywords: sentinel lymph node biopsy; mouth neoplasms; sensitivity; specificity; survival

\section{Introduction}

Oral squamous cell carcinoma (OSCC) is the 11th most common cancer in the world [1] and it accounts for 128,000 deaths each year [2]. In the early stage of OSCC (T1-T2/NO) the presence of metastasis lymph nodes reduces the patient's survival by $50 \%$ and it is one of the most important adverse indicators of the disease's prognosis [3-5]. Furthermore, it has been calculated that there is a risk of ganglionic affectation in around $20-30 \%$ of the cases [2,6-8]; therefore, the correct staging of lymph nodes is crucial for the patient's therapeutic development. Given that modern image techniques (ultrasound, computed tomography, positron emission tomography and magnetic resonance imaging) $[9,10]$ and physical palpation are not sensitive enough to be able to determine the definitive position of the lymph node, associated surgical techniques must be used [4,11-13].

The therapeutic management of OSCC in T1-T2/NO remains a controversial topic. One of the most historically recognised techniques, which is also used in staging, is the lateral neck dissection $(3,5,10)$; a technique that has produced better survival rates than 
those attained when enforcing the "watch and wait" approach [6]; nonetheless, 70-80\% of the patients who are subjected to this technique do not receive any kind of benefit $[11,13]$ given that they do not present with hidden metastatic lymph nodes [14] and, as a result, these patients are exposed to a series of associated postoperative risks, such as shoulder pain and spinal nerve damage [4] that reduce their quality of life [8].

That is why the sentinel lymph node technique (SLNB) has been introduced in OSCC as a much less invasive [12] technique for the adequate staging of the lymph nodes that avoids the postoperative morbidity inherent to lateral dissection [15]. This technique is widely recognised and accepted in the treatment of breast cancer [16] and melanoma [17]; however, in the treatment of head and cervical cancer (HNC), it is only considered as an alternative to lateral neck dissection [4].

The technique shows that, in those patients in which the sentinel nodes (SN), that is to say, the nodes into which the tumour cells will drain from the primary tumour [5] are free of metastasis, it is unlikely that other hidden nodes exist in the lymphatic chain [18]. Therefore, following the local surgical excision of the tumour and the $\mathrm{SN}$, the patient will be completely free of the disease. In the event in which a metastatic affection is present in the lymph nodes, a neck dissection would be required [19]. A considerable number of studies have been published that show a sensitivity and negative predictive values of between $91-95 \%$ and $90-98 \%$, respectively $[4,15,20]$. On the other hand, in the random trial by D'cruz et col which observed a sample of 596 patients, the overall survival after three years in patients who underwent this technique was $80 \%$ compared with $67.5 \%$ in patients who did not undergo this technique [21].

Lastly, the purpose of this study was to analyse the diagnostic and prognostic efficiency of the SLNB technique in patients with OSCC T1-T2/N0, as well as evaluating the overall survival.

\section{Materials and Methods}

\subsection{Study Design}

This is a prospective observational study, performed by the Maxillo-Facial Surgery Unit of the University Hospital Complex in Santiago de Compostela (CHUS) in Spain. This study was approved by the Autonomous Ethics Committee of Galicia (Spain) under reference 2020/222. This study has been designed according to the STROBE recommendations [22]. The information was gathered between February 2013 and June 2020, which was the last follow-up date. All of the procedures were performed with the understanding and written consent of all of the subjects, in accordance with Helsinki Declaration and its subsequent modifications.

\subsection{Calculation of Sample Size}

According to the hospital's records, there is an average of 10 stage $\mathrm{T} 1$ and $\mathrm{T} 2$ tumours that could be treated using the SLNB each year and there is an average of 200 stage 3 and 4 tumours each year. For a 7-year study, with a sample of 60 patients, and based on the comparison of proportions for a population of 1000 patients, with an expected proportion of $10.0 \%$ and a confidence level of $95.0 \%$, the precision would be 5.578 . This sample size has been calculated using Epidat 4.2 (SERGAS, Galicia, Spain).

\subsection{Study Population, Inclusion, and Exclusion Criteria}

The study included 60 subjects who were recruited prospectively. The inclusion criteria were: patients over the age of 18 , of both sexes, who had been diagnosed with OSCC in stage T1/T2NOM0 and who had undergone the SLNB technique following the CHUS protocol. The minimum follow-up period was six months after the $\mathrm{SN}$ technique had been performed. The exclusion criteria were: patients with tumours in advanced stages (T3/T4), patients with oral metastasis from other tumours, patients who had undergone a previous surgical procedure and who were in clinical relapse, patients with a tumour 
with a different histopathological origin than OSCC, and patients who refused to sign the specific informed consent form.

\subsection{Marking and Study of the Tumour's Lymphatic Drainage}

The presurgical localization of the SN was performed in all patients following the European Association of Nuclear Medicine (EAMN)'s guidelines for a 2-day protocol study [2]. The day before the surgical procedure, a dose of $3 \mathrm{mCi}(111 \mathrm{MBq})$ of Thecnecium-99mlabelled nanocolloids (99mTc-nanocolloid) was administered to each patient, distributed in four injections covering each of the cardinal points around the tumour. Planar images were taken using a GE Millennium VG gamma camera in the first 60 min after the injection (LEHR collimator, energy-peak $140 \mathrm{KeV}$ with $20 \%$ window, zoom $1256 \times 256$ matrix). Where required, and after the planar images had been taken, a SPECT-TC cervical image was also taken using a GE Optima NM/CT 640 gamma camera. During the surgical procedure, intraoperative lymphatic mapping was performed using a portable gamma-probe for radio guidance (Navigator GPS gamma probe) in order to identify the "hot spots" corresponding to the SN. The primary tumour was often resected first, particularly in those cases in which the primary tumour was close to potential adjacent SLNs in order to avoid the "shine-through effect" that would cause the nearby radioactive SLNs to be occulted by the activity of the primary lesion, therefore limiting the accuracy of the SLN detection. After the SLNs were removed, the surgical field was scanned to ensure that no SLNs were left. SNLs were considered as any node with an uptake higher than $10 \%$ of the ex-vivo counts of the hottest node.

All of the extracted lymph nodes were sent to the Pathological Anatomy Service for their histopathological study. If no OSCC metastasis was observed in the histological study of the lymph nodes, the patient did not undergo the neck dissection procedure and they were followed up on a regular basis. If metastasis did appear, the patient was considered to be at an advanced stage.

\subsection{Histopathological Study of Sentinel Nodes (SN)}

Each SN node was formalin-fixed, bisected and each half was routinely processed and paraffin-embedded. For the immunohistochemical study, each block was trimmed by 50 to 100 micrometres, depending on the thickness of the lymph node, and ten three-micrometre tissue sections were taken to special immunohistochemistry-coated slides (Agilent Dako, Santa Clara, CA, USA). The sections were stained as follows: No. 1, 2, 4-7, 9 and 10 with haematoxylin-eosin and 3 and 8 with cytokeratin.

For the immunohistochemistry (IHC) analysis we used Cytokeratin AE1 / AE3 (Clone AE1/AE3, FLEX Ready to use, Agilent Dako, Santa Clara, California (CA), USA), with automated equipment (Omnis, Dako, Santa Clara, CA, USA). To summarise, the epitope retrieval was performed in $10 \mathrm{mM}$ sodium citrate buffer ( $\mathrm{pH}$ 9.0) using a water bath for $40 \mathrm{~min}$ at $95-99^{\circ} \mathrm{C}$. Endogenous peroxidase was blocked with a peroxidase-blocking reagent (Agilent Dako, Santa Clara, CA, USA) for $5 \mathrm{~min}$. Incubation with the primary antibody was performed at room temperature for $20 \mathrm{~min}$ and the staining was revealed with EnVision (20 min) and DAB (10 min) (Agilent Dako, Santa Clara, CA, USA). Finally, they were counterstained with HE for 15 min.

\subsection{Information and Variables}

Information was gathered at different stages of the treatment: pre-surgical, surgical, post-surgical and follow-up, and, likewise the following clinical, histopathological and follow-up details were recorded: sex, age, location, TNM (Tumor Node Metastasis), T1 or $\mathrm{T} 2$, classification, type of cervical surgical treatment, largest size of $\mathrm{SN}\left(\mathrm{cm}^{2}\right)$, histopathological involvement of SN (negative, micrometastasis, macrometastasis), clinical relapse and death. The following dates were gathered for the follow-up assessment: birth, surgery, relapse, successes, therefore making it possible to calculate the follow-up time, diseasespecific survival (DSS), disease-free survival (DFS). The diagnostic indices were calculated: 
true positives (TP), true negatives (TN), false positives (FP), false negatives (FN), positive predictive value (PPV), sensitivity, specificity and negative predictive value (NPV).

\subsection{Statistical Analysis}

The variables were expressed as a frequency and a percentage or mean \pm standard deviation (SD). $2 \times 2$ tables were built to determine the diagnostic indices. The Chi-square was used to establish the relationship between mortality and SN. Student's $t$-test was used to examine the relationship between the DSS and DFS with SN. ROC (Receiver Operating Characteristic) curves were constructed to determine the area under the curve (AUC), the sensitivity and specificity. The Kaplan-Meier curve and the log-rank statistic test were used to estimate survival. Multinomial logistic regression models were constructed to determine the risk of mortality using OR (odds ratio). The statistical analyses were made with IBM SPSS 23 software (IBM Inc., Madrid, Spain). The significance level was established at $p<0.05$.

\section{Results}

The final sample consisted of 60 patients, 28 (46.7\%) men and 32 (53.3\%) women, with an average age of $66.9 \pm 12.3$ years old and a range from 34.9 to 92 years old. 60 tumours were operated on with the SN technique, 32 (53.3\%) in stage T1 and 28 (46.7\%) in stage T2. Tables 1 and 2 includes all of the clinical and histopathological data and monitoring of the sample. The average monitoring time was $42.8 \pm 23.1$ months (from 0.6 to 87.3 months).

Table 1. Descriptive summary of the qualitative variables of the patients included in the study.

\begin{tabular}{|c|c|c|c|}
\hline \multicolumn{2}{|l|}{ Variables } & \multirow{3}{*}{$\begin{array}{c}\text { Number } \\
28 \\
32\end{array}$} & \multirow{3}{*}{$\begin{array}{c}\% \\
46.7 \\
53.3\end{array}$} \\
\hline & Male & & \\
\hline Gender & Female & & \\
\hline \multirow{9}{*}{ Location } & Tongue & 24 & 40.0 \\
\hline & Floor of mouth & 13 & 21.7 \\
\hline & Buccal mucosa & 8 & 13.3 \\
\hline & Retromolar trigone & 3 & 5.0 \\
\hline & Gum & 4 & 6.7 \\
\hline & Hard palate & 1 & 1.7 \\
\hline & Soft palate & 1 & 1.7 \\
\hline & Alveolar ridge & 5 & 8.3 \\
\hline & Upper lip & 1 & 1.7 \\
\hline \multirow{2}{*}{ TNM(Tumor, Nodes, Metastases) } & $\mathrm{T} 1$ & 32 & 53.3 \\
\hline & $\mathrm{T} 2$ & 28 & 46.7 \\
\hline \multirow{2}{*}{ SN (Sentinel Node) } & Negative & 50 & 83.3 \\
\hline & Positive & 10 & 16.7 \\
\hline \multirow{2}{*}{ Neck Metastasis Post-SN } & No & 46 & 76.7 \\
\hline & Yes & 14 & 23.3 \\
\hline \multirow{3}{*}{ Histopathological Lymph Node Description } & Negative & 50 & 83.3 \\
\hline & Micrometastasis & 2 & 3.3 \\
\hline & Macrometastasis & 8 & 13.3 \\
\hline \multirow{3}{*}{ Histopathological Lymph Node Affectation } & Subcapsular & 8 & $(80)$ \\
\hline & Intraparenchymal & 1 & (10) \\
\hline & Complete (both) & 1 & $(10)$ \\
\hline
\end{tabular}


Table 1. Cont.

\begin{tabular}{cccc}
\hline Variables & & Number & $\mathbf{\%}$ \\
\hline \multirow{2}{*}{ Extracapsular Affectation } & No & 9 & $(90)$ \\
& Yes & 1 & $(10)$ \\
\hline \multirow{2}{*}{ Neck Treatment } & No treatment & 50 & 83.3 \\
& Functional dissection & 10 & 16.7 \\
\hline \multirow{2}{*}{ Development } & Stable & 32 & 53.3 \\
& Relapse & 17 & 28.3 \\
& Recurring Relapse & 1 & 1.7 \\
& Death & 10 & 16.7 \\
\hline \multirow{2}{*}{ Locoregional Recurrence } & No & 38 & 63.3 \\
& Yes & 22 & 36.7 \\
\hline \multirow{2}{*}{ Death } & No & 42 & 70.0 \\
& Yes & 12 & 20.0 \\
& Yes, for other reasons & 6 & 10.0 \\
\hline
\end{tabular}

Table 2. Descriptive summary of the quantitative variables of the patients included in the study.

\begin{tabular}{|c|c|c|}
\hline & Average (SD) & Minimum-Maximum \\
\hline Age of Diagnosis (Years) & $66.9(12.3)$ & $34.9-92.0$ \\
\hline SN Size $\left(\mathrm{cm}^{2}\right)$ & $1.7(2.7)$ & $0.1-17.6$ \\
\hline $\begin{array}{ll} & \text { Follow-up Time (months) } \\
\text { - } & \mathrm{SN}-\text { (sentinel node negative) } \\
\text { - } & \mathrm{SN}+(\text { sentinel node positive) }\end{array}$ & $\begin{array}{l}42.8(23.1) \\
43.8(21.8) \\
38.1(29.7)\end{array}$ & $\begin{array}{l}0.6-87.3 \\
0.6-82.8 \\
6.7-87.3\end{array}$ \\
\hline $\begin{array}{cc}\text { Specific Survival (months) } \\
\bullet \quad \mathrm{SN}- \\
\bullet \quad \mathrm{SN}+\end{array}$ & $\begin{array}{l}24.8(19.3) \\
27.2(22.8) \\
21.1(12.5)\end{array}$ & $\begin{array}{l}0.6-76.6 \\
0.6-82.8 \\
6.7-43.5\end{array}$ \\
\hline $\begin{array}{cc}\text { Disease-Free Survival (months) } \\
\bullet \quad \mathrm{SN}- \\
\bullet \quad \mathrm{SN}+\end{array}$ & $\begin{array}{l}15.9(13.3) \\
17.0(15.1) \\
13.6(8.9)\end{array}$ & $\begin{array}{l}1.8-61.3 \\
3.9-61-3 \\
1.8-29.9\end{array}$ \\
\hline
\end{tabular}

With regards to hidden metastasis, 10 patients $(16.7 \%)$ presented with $\mathrm{SN}+$ (sentinel node positive). The average macroscopic diameter was $1.74 \pm 2.68 \mathrm{~cm}^{2}$ (from $0.1-17.6 \mathrm{~cm}^{2}$ ). At the histopathological level, the average number of focal points was $1.30 \pm$ (from 1 to 2 maximum) with an average maximum diameter of $4.62 \pm 4.62 \mathrm{~mm}$ (range from 0.2 to $15 \mathrm{~mm})$. The majority $(80 \%)$ only presented subcapsular affection; however, one case also presented with extracapsular affection.

With regards to mortality, out of the $50 \mathrm{SN}$ - patients, $39(78 \%)$ survived, $6(12 \%)$ died due to the neoplastic process and $5(10 \%)$ died due to causes unrelated to the tumour. Out of the $10 \mathrm{SN}+$ patients, $3(30 \%)$ survived, $6(60 \%)$ died from cancer and $1(10 \%)$ died from non tumour-related causes. The survival of $\mathrm{SN}-$ patients was higher than $\mathrm{SN}+$ patients in this follow-up period $(p=0.002)$.

The DSS for the SN- patients was $27.2 \pm 22.8$ months and $21.1 \pm 12.5$ months for $\mathrm{SN}+$ patients; the DFS was $17.0 \pm 15.1$ months for $\mathrm{SN}$ - patients and $13.6 \pm 8.9$ months for $\mathrm{SN}+$ patients. Using the Kaplan-Meier curves, we determined that the average survival estimation for $\mathrm{SN}-$ patients was 74.0 months (CI95\% 67.6-80.5) and it was 45.4 months $(\mathrm{CI} 95 \% 10.9-24.0)(p=0.002)$ for $\mathrm{SN}+$ patients (Figure 1). Using the proportional hazards model, we determined that sex played a significant role in the survival time, with women 
presenting a $\mathrm{HR}=5.889$ (CI95\% 1.01-31.500; $p=0.038)$ (Figure 1B). However, $\mathrm{SN}$ does not offer significant differences in the DFS for locoregional recurrence.

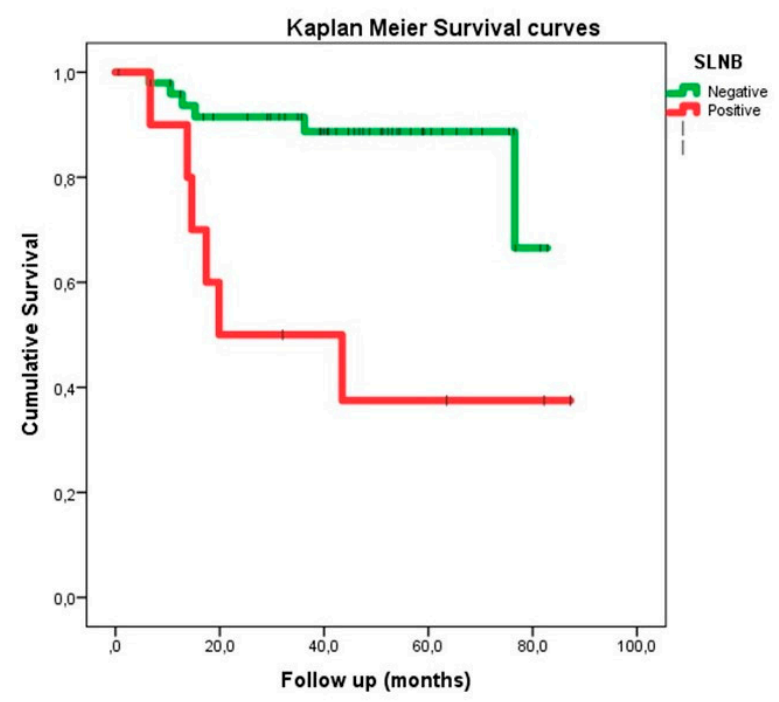

(A)

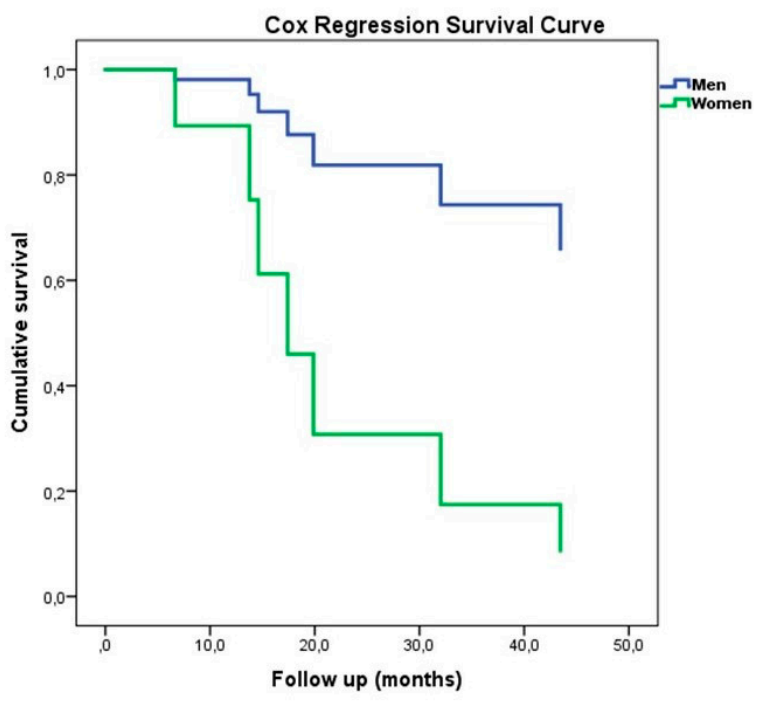

(B)

Figure 1. Kaplan-Meier (A) and Cox (B) survival curves. (SLNB: Sentinel lymph node biopsy technique).

By using logistic regression, we determined that $\mathrm{SN}+$ patients presented an $\mathrm{OR}=11.00$ (CI95\% 2.393-50.589, $p=0.002)$ for cancer-related mortality. When we adjusted the regression model to a location different to the tongue and stage T2, the OR for mortality in SN+ patients was 28.75 (CI95\% 2.71-305.62, $p=0.005$ ) (Table 3).

Table 3. A univariate logistic regression analysis was performed to determine the univariate OR for death. The statistical analysis of the adjusted OR was performed using gradual multivariate logistic regression adjusted for SLN, location and TNM. SLN: sentinel lymph node; OR: Odds Ratio.

\begin{tabular}{ccccc}
\hline \multirow{2}{*}{ Covariate } & \multicolumn{3}{c}{ Death } \\
\cline { 2 - 5 } & Univariate OR (95\% CI) & $p$ Value & Adjusted OR (95\% CI) & $p$ Value \\
\hline $\begin{array}{c}\text { SLN (Sentinel Lymph Node) } \\
\text { Positive vs. Negative }\end{array}$ & $11.00(2.39-50.59)$ & 0.002 & $28.75(2.71-305.62)$ & 0.005 \\
\hline $\begin{array}{c}\text { Location } \\
\text { Other vs. Tongue }\end{array}$ & $4.23(0.84-21.40)$ & 0.081 & $18.61(1.34-258.65)$ & 0.029 \\
\hline $\begin{array}{c}\text { TNM } \\
\text { T2 vs. T1 }\end{array}$ & $4.58(1.10-19.11)$ & 0.037 & $5.15(0.86-30.72)$ & 0.072 \\
\hline
\end{tabular}

In terms of the diagnostic performance of the $\mathrm{SN}$ test, based on TVP $=10, \mathrm{TVN}=42$, TFP $=0$ and TFN $=8,55 \%$ sensitivity, $100 \%$ specificity, $100 \%$ PPV and $84 \%$ NPV were obtained. The analysis using ROC curves revealed an AUC $=0.671$ (CI95\% 0.492-0.850, $p=0.046$ ) (Figure 2). 


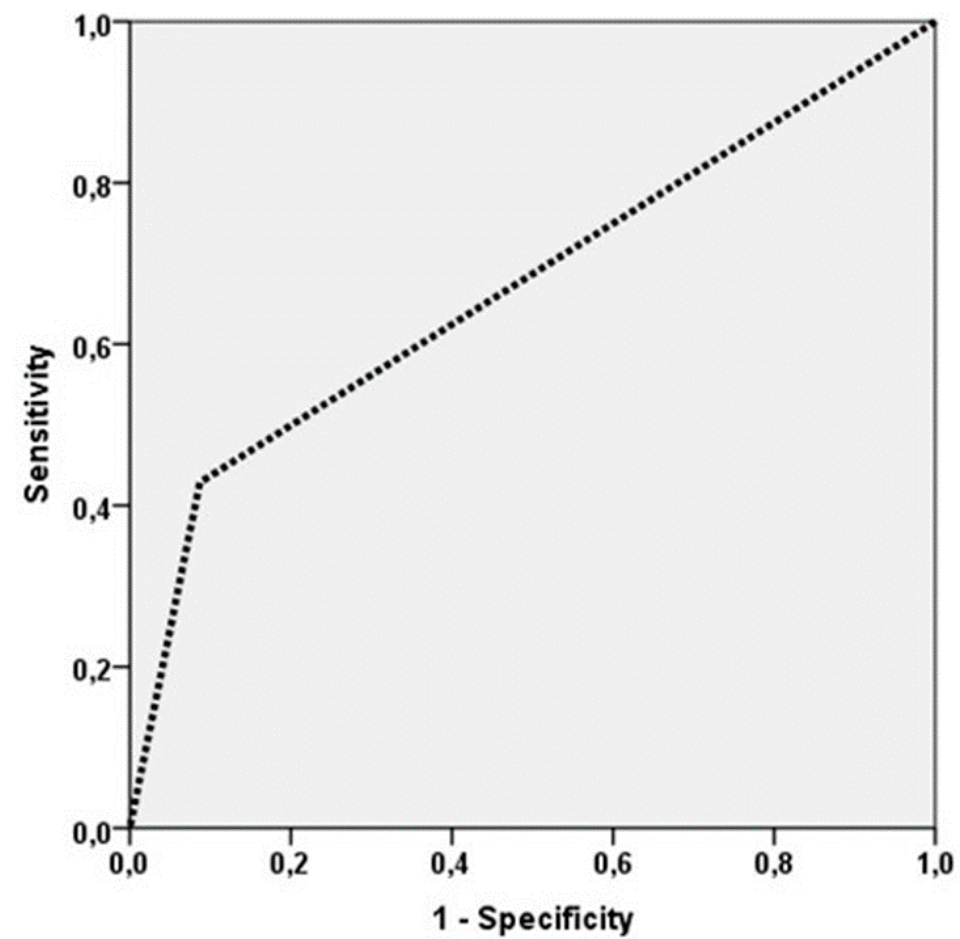

Figure 2. ROC curve for the sentinel lymph node biopsy (SLNB) technique, representing the sensitivity and 1-Specificity.

\section{Discussion}

In this study, a greater and significant survival of $\mathrm{SN}-$ patients was determined: $78 \%$ compared to $30 \%$ of the $\mathrm{SN}+$ patients. In quantitative terms, the mean survival estimation for $\mathrm{SN}$ - patients was 74.0 months (CI95\% 67.6-80.5) and for $\mathrm{SN}+$ patients it was 45.4 months (CI95\% 10.9-24.0). For cancer-related mortality, SN+ patients presented an OR of 11.0, and this figure reached 28.75 for T2 cases. The SLNB reached a sensitivity of $55 \%$, however the NPV of $84 \%$ is particularly worth mentioning.

SNLB is based on the early detection and correct staging of neck lymph node involvement, since multiple studies have shown that lymph node involvement is decisive for patient survival [3-6]. In addition, it is not only crucial for survival, but it is also a factor that will determine the patient's quality of life, when taking into consideration the side effects of the other different treatment options [14].

One of the most relevant figures for the assessment of SLNB is the overall survival, in our study the overall survival of SN+ patients was $40 \%$, which was significantly lower than the overall survival of SN- patients $(p=0.002)$. Kovács et al. [23] also described an overall survival of $38 \%$ for $\mathrm{SN}+$ patients and $85 \%$ for $\mathrm{SN}$ - patients, very similar figures to those obtained in this study. The Sentinel European Node Trial (SENT), a prospective multicentre study (7), put the 3-year overall survival of SN- at $88 \%$. However, some studies have shown fewer differences between groups. For example, Flanch G.B et al.'s [24] German multicentre study with $\mathrm{n}=62$, showed an exceptional 5-year overall survival for both SN+ patients $(79.7 \%)$ and $\mathrm{SN}-$ patients $(92.7 \%)$. In their sample of 234 patients, Moya-plana et al. [4] observed that the overall survival of SN- patients at five years was $77.3 \%$, and Cramer et al. [20] observed an overall survival of SN- patients of $82 \%$, figures similar to those obtained in this study. Furthermore, according to the data obtained in more recent studies, there is a higher probability of mortality in SN+ patients [25]. In our study there was also a significant difference in the estimated survival times of patients who obtained SLN+ and SLN-, with these recorded at 45.4 months and 74, respectively.

Furthermore, the sensitivity of a diagnostic test is essential in order to determine which patients are truly ill, and this figure is among the most reported in studies, although the NPV is much more decisive. Specifically, in our study, of the 50 patients diagnosed 
with $\mathrm{SN}-, 10$ were given a posteriori diagnosis of hidden lymphatic metastasis, obtaining a NPV of $84 \%$ and a sensitivity of $55 \%$. This datum is similar to that presented by Ahmed Al-Dam et al. (19), who reached a sensitivity of 50\%. However, it is in contrast to other studies, such the retrospective study of 70 patients by E. Martilla et al. [3] who presented a test sensitivity of $80 \%$ and a NPV of $97 \%$; likewise, the study by Loree et al. [25] offered very similar results with a sensitivity of $75 \%$ and a NPV of $91 \%$. Very similar data was also extracted from the multicentre studies performed by Schilling et al. [7] $(\mathrm{n}=415)$, Vishnoi JR et al. [26] ( $\mathrm{n}=134)$ and Den Toom et al. [27] with a sensitivity of $86 \%, 93 \%$ and $97 \%$, respectively. Some recent meta-analyses $[28,29]$ reported up to $95 \%$ sensitivity $[5,13]$. These results highlights the sentinel node biopsy as a reliable diagnostic staging technique for the clinically negative neck patients with early-stage oral squamous cell carcinoma. However, it is evident that there is a high discrepancy in the different values reported in the literature with these ranging from $55 \%$ to $100 \%$ [30].

There are a number of factors that determine the variability in the diagnostic performance values of the SLNB: work centre, type of tumour sample (HNC or only OSCC from the oral cavity), follow-up period, date of publication of the studies and the performance of serial SN cuts with or without IHC. According to Liu et al. [29] the subgroup analysis based on IHC indicated that $\mathrm{H}$ and $\mathrm{E}$ staining combined with IHC was significantly more sensitive that the results obtained when H\&E staining was performed on its own, with a sensitivity of 0.88 (CI 95\%: 0.86 to 0.90 ) vs. 0.77 (CI 95\%: 0.68 to 0.85 ). Furthermore, the early publication subgroup (2000 a 2008) had a better combined sensitivity than the late publication subgroup (2009 to 2016) (0.92 [0.87-0.95] vs. 0.86 [0.83-0.88].

According to Liao et al.'s [31] recent meta-analysis, which contained 73 articles on $\mathrm{HNCs}$, it appears that, despite its limitations, when compared with other techniques SLNB presents the best results for detecting hidden metastases. The sensitivity for fine needle aspiration (FNA) puncture was $56.4 \%$, it was $84.9 \%$ for SLNB, $47 \%$ for computed tomography (CT), 56.6\% for MRI, $48.3 \%$ for PET and $63.3 \%$ for ultrasound.

This work contributes to improving knowledge in the field of SLNB of tumours of the oral cavity, supporting the European Association for Craniomaxillofacial Surgery (EACMFS) guidelines for the management of clinically N0 tumours, The strength of this study is that it boasts a follow-up period of longer than 3 years and a histopathological analysis technique combined with IHC. The limitations of this study include its modest sample size, given that it was a single-centre study and the inherent limitations of possible diagnostic bias.

\section{Conclusions}

Patient mortality in T1/T2-N0 remains very high. The use of the SLNB in these patients seems to have an adequate sensitivity for the detection of hidden metastases. The histopathological study by immunohistochemical analysis seems to be key for the determination of micrometastasis and in the improvement of the diagnostic cost-effectiveness of the test. A definitive protocolisation of the SLNB technique in OSCC seems to be necessary.

Author Contributions: Conceptualization, A.G.-G. and M.P.-S.; methodology, M.S.-A., J.M.S.-P., M.G.-P.; validation, all the authors; formal analysis, C.M.C.-P., M.P.-S. and M.S.-A.; investigation, all the authors; resources, A.G.-G. and J.M.S.-P.; data curation, M.P.-S., J.M.S.-M. and C.M.C.-P.; writing—original draft preparation, M.P.-S., J.M.S.-M. and M.S.-A.; writing—review and editing, all the authors; supervision, and project administration, M.P.-S. All authors have read and agreed to the published version of the manuscript.

Funding: This research received no external funding.

Institutional Review Board Statement: The study was conducted according to the guidelines of the Declaration of Helsinki, and approved by the Ethics Committee of Galicia (Spain) under reference $2020 / 222$

Informed Consent Statement: Informed consent was obtained from all subjects involved in the study. 
Conflicts of Interest: The authors declare no conflict of interest.

\section{References}

1. Hutchison, I.L.; Ridout, F.; Cheung, S.M.Y.; Shah, N.; Hardee, P.; Surwald, C.; Thiruchelvam, J.; Cheng, L.; Mellor, T.K.; Brennan, P.A.; et al. Nationwide randomised trial evaluating elective neck dissection for early stage oral cancer (SEND study) with meta-analysis and concurrent real-world cohort. Br. J. Cancer 2019, 121, 827-836. [CrossRef]

2. Giammarile, F.; Schilling, C.; Gnanasegaran, G.; Bal, C.; Oyen, W.J.G.; Rubello, D.; Schwarz, T.; Tartaglione, G.; Miller, R.N.; Paez, D.; et al. The EANM practical guidelines for sentinel lymph node localisation in oral cavity squamous cell carcinoma. Eur. J. Nucl. Med. Mol. Imaging 2019, 46, 623-637. [CrossRef]

3. Marttila, E.; Keski-Säntti, H.; Hagström, J.; Snäll, J.; Wilkman, T. Sentinel lymph node biopsies in early stage oral and oropharyngeal carcinoma: A retrospective single-centre experience. Br. J. Oral. Maxillofac. Surg. 2020, 58, 1078-1083. [CrossRef]

4. Moya-Plana, A.; Aupérin, A.; Guerlain, J.; Gorphe, P.; Casiraghi, O.; Mamelle, G.; Melkane, A.; Lumbroso, J.; Janot, F.; Temam, S. Sentinel node biopsy in early oral squamous cell carcinomas: Long-term follow-up and nodal failure analysis. Oral Oncol. 2018, 82, 187-194. [CrossRef]

5. Govers, T.M.; Hannink, G.; Merkx, M.A.; Takes, R.P.; Rovers, M. Sentinel node biopsy for squamous cell carcinoma of the oral cavity and oropharynx: A diagnostic meta-analysis. Oral Oncol. 2013, 49, 726-732. [CrossRef]

6. Holden, A.; Sharma, D.; Schilling, C.; Gnanasegaran, G.; Odell, E.; Sassoon, I.; McGurk, M. Biopsy of the sentinel lymph node in oral squamous cell carcinoma: Analysis of error in 100 consecutive cases. Br. J. Oral Maxillofac. Surg. 2018, 56, 615-620. [CrossRef]

7. Schilling, C.; Stoeckli, S.J.; Haerle, S.K.; Broglie, M.A.; Huber, G.F.; Sørensen, J.A.; Bakholdt, V.; Krogdahl, A.; von Buchwald, C.; Bilde, A.; et al. Sentinel European Node Trial (SENT): 3-year results of sentinel node biopsy in oral cancer. Eur. J. Cancer 2015, 51, 2777-2784. [CrossRef] [PubMed]

8. Civantos, F.J.; Zitsch, R.P.; Schuller, D.E.; Agrawal, A.; Smith, R.B.; Nason, R.; Petruzelli, G.; Gourin, C.G.; Wong, R.J.; Ferris, R.L.; et al. Sentinel lymph node biopsy accurately stages the regional lymph nodes for T1-T2 oral squamous cell carcinomas: Results of a prospective multi-institutional trial. J. Clin. Oncol. 2010, 28, 1395-1400. [CrossRef] [PubMed]

9. Christensen, A.; Bilde, A.; Therkildsen, M.H.; Mortensen, J.; Charabi, B.; Kirkegaard, J.; Specht, L.; Von Buchwald, C. The prevalence of occult metastases in nonsentinel lymph nodes after step-serial sectioning and immunohistochemistry in cN0 oral squamous cell carcinoma. Laryngoscope 2011, 121, 294-298. [CrossRef] [PubMed]

10. Melkane, A.E.; Mamelle, G.; Wycisk, G.; Temam, S.; Janot, F.; Casiraghi, O.; Lumbroso, J. Sentinel node biopsy in early oral squamous cell carcinomas: A 10-year experience. Laryngoscope 2012, 122, 1782-1788. [CrossRef]

11. Chung, M.K.; Lee, G.J.; Choi, N.; Cho, J.-K.; Jeong, H.-S.; Baek, C.-H. Comparative study of sentinel lymph node biopsy in clinically N0 oral tongue squamous cell carcinoma: Long-term oncologic outcomes between validation and application phases. Oral Oncol. 2015, 51, 914-920. [CrossRef]

12. Boeve, K.; Schepman, K.; Schuuring, E.; Roodenburg, J.; Halmos, G.; van Dijk, B.A.; Boorsma, R.; de Visscher, J.; Brouwers, A.; van der Vegt, B.; et al. High sensitivity and negative predictive value of sentinel lymph node biopsy in a retrospective early stage oral cavity cancer cohort in the Northern Netherlands. Clin. Otolaryngol. 2018, 43, 1080-1087. [CrossRef] [PubMed]

13. Thompson, C.F.; John, M.A.S.; Lawson, G.; Grogan, T.; Elashoff, D.; Mendelsohn, A.H. Diagnostic value of sentinel lymph node biopsy in head and neck cancer: A meta-analysis. Eur. Arch. Oto-Rhino-Laryngol. 2012, 270, 2115-2122. [CrossRef] [PubMed]

14. Rigual, N.; Loree, T.; Frustino, J.; Jayaprakash, V.; Cohan, D.; Sullivan, M.; Kuriakose, M.A. Sentinel node biopsy in lieu of neck dissection for staging oral cancer. JAMA Otolaryngol. Neck Surg. 2013, 139, 779-782. [CrossRef]

15. Rigual, N.; Douglas, W.; Lamonica, D.; Wiseman, S.; Cheney, R.; Hicks, W.; Loree, T. Sentinel lymph node biopsy: A rational approach for staging T2N0 oral cancer. Laryngoscope 2005, 115, 2217-2220. [CrossRef]

16. Lyman, G.H.; Temin, S.; Edge, S.B.; Newman, L.A.; Turner, R.R.; Weaver, D.L.; Benson, A.B.; Bosserman, L.D.; Burstein, H.J.; Cody, H.; et al. Sentinel lymph node biopsy for patients with early-stage breast cancer: American society of clinical oncology clinical practice guideline update. J. Clin. Oncol. 2014, 32, 1365-1383. [CrossRef] [PubMed]

17. Wong, S.L.; Faries, M.B.; Kennedy, E.B.; Agarwala, S.S.; Akhurst, T.J.; Ariyan, C.; Balch, C.M.; Berman, B.S.; Cochran, A.; Delman, K.A.; et al. Sentinel lymph node biopsy and management of regional lymph nodes in melanoma: American society of clinical oncology and society of surgical oncology clinical practice guideline update. J. Clin. Oncol. 2018, 36, 399-413. [CrossRef] [PubMed]

18. Gallegos-Hernández, J.-F.; Hernández-Hernández, D.-M.; Flores-Díaz, R.; Sierra-Santiesteban, I.; Pichardo-Romero, P.; AriasCeballos, H.; Minauro-Muñoz, G.; Alvarado-Cabrero, I. The number of sentinel nodes identified as prognostic factor in oral epidermoid cancer. Oral Oncol. 2005, 41, 947-952. [CrossRef]

19. Al-Dam, A.; Precht, C.; Barbe, A.; Kohlmeier, C.; Hanken, H.; Wikner, J.; Schön, G.; Heiland, M.; Assaf, A.T. Sensitivity and specificity of sentinel lymph node biopsy in patients with oral squamous cell carcinomas using indocyanine green fluorescence imaging. J. Craniomaxillofac. Surg. 2018, 46, 1379-1384. [CrossRef] [PubMed]

20. Cramer, J.D.; Sridharan, S.; Ferris, R.L.; Duvvuri, U.; Samant, S. Sentinel lymph node biopsy versus elective neck dissection for stage I to II oral cavity cancer. Laryngoscope 2019, 129, 162-169. [CrossRef]

21. D'Cruz, A.K.; Vaish, R.; Kapre, N.; Dandekar, M.; Gupta, S.; Hawaldar, R.; Agarwal, J.P.; Pantvaidya, G.; Chaukar, D.; Deshmukh, A.; et al. Elective versus therapeutic neck dissection in nodenegative oral cancer. N. Engl. J. Med. 2015, 373, 521-529. [CrossRef] [PubMed] 
22. von Elm, E.; Altman, D.G.; Egger, M.; Pocock, S.J.; Gøtzsche, P.C.; Vandenbroucke, J.P. The Strengthening the Reporting of Observational Studies in Epidemiology (STROBE) statement: Guidelines for reporting observational studies. Int. J. Surg. 2014, 12, 1495-1499. [CrossRef]

23. Kovács, A.F.; Stefenelli, U.; Seitz, O.; Middendorp, M.; Diener, J.; Sader, R.; Grünwald, F. Positive sentinel lymph nodes are a negative prognostic factor for survival in T1-2 oral/oropharyngeal cancer-A long-term study on 103 patients. Ann. Surg. Oncol. 2008, 16, 233-239. [CrossRef] [PubMed]

24. Flach, G.B.; Bloemena, E.; Klop, W.M.C.; van Es, R.J.; Schepman, K.-P.; Hoekstra, O.S.; Castelijns, J.A.; Leemans, C.R.; de Bree, R. Sentinel lymph node biopsy in clinically N0 T1-T2 staged oral cancer: The Dutch multicenter trial. Oral Oncol. 2014, 50, 1020-1024. [CrossRef] [PubMed]

25. Loree, J.T.; Popat, S.R.; Burke, M.S.; Frustino, J.; Ba, J.S.G.; Loree, T.R. Sentinel lymph node biopsy for management of the N0 neck in oral cavity squamous cell carcinoma. J. Surg. Oncol. 2019, 120, 101-108. [CrossRef]

26. Vishnoi, J.; Kumar, V.; Gupta, S.; Chaturvedi, A.; Misra, S.; Akhtar, N.; Agarwal, P.; Jamal, N.; Pareek, P. Outcome of sentinel lymph node biopsy in early-stage squamous cell carcinoma of the oral cavity with methylene blue dye alone: A prospective validation study. Br. J. Oral Maxillofac. Surg. 2019, 57, 755-759. [CrossRef]

27. Den Toom, I.J.; Heuveling, D.A.; Flach, G.B.; van Weert, S.; Karagozoglu, K.H.; van Schie, A.; Bloemena, E. Sentinel node biopsy for early-stage oral cavity cancer: The VU University Medical Center experience. Head Neck 2015, 4, 573-578. [CrossRef]

28. Yang, Y.; Zhou, J.; Wu, H. Diagnostic Value of sentinel lymph node biopsy for cT1/T2N0 tongue squamous cell carcinoma: A meta-analysis. Eur. Arch. Otorhinolaryngol. 2017, 274, 3843-3852. [CrossRef]

29. Liu, M.; Wang, S.J.; Yang, X.; Peng, H. Diagnostic efficacy of sentinel lymph node biopsy in early oral squamous cell carcinoma: A meta-analysis of 66 studies. PLoS ONE 2017, 12, e0170322. [CrossRef]

30. Dequanter, D.; Shahla, M.; Paulus, P.; Lothaire, P. Long term results of sentinel lymph node biopsy in early oral squamous cell carcinoma. Onco. Targets Ther. 2013, 6, 799-802. [CrossRef]

31. Liao, L.-J.; Hsu, W.-L.; Wang, C.-T.; Lo, W.-C.; Lai, M.-S. Analysis of sentinel node biopsy combined with other diagnostic tools in staging cN0 head and neck cancer: A diagnostic meta-analysis. Head Neck 2015, 38, 628-634. [CrossRef] [PubMed] 